\title{
Yeni Nesil Cep Telefonu Frekansları ve Biyolojik Etkileri
}

\section{New Generation Mobile Phone Frequencies and Biological Effects}

iD Yusuf Küçükbağrıaçık ${ }^{1}$, iD Elçin Özgür Büyükatalay ${ }^{1}$

${ }^{1}$ Gazi Üniversitesi Tıp Fakültesi, Biyofizik Anabilim Dalı, Ankara, Türkiye

\section{$\ddot{O} z$}

Her geçen gün artan miktarda etrafımızı saran kablosuz teknolojilerin sağlık ve biyolojik etkileri ile ilgili henüz kesin bir bilgi bulunmamaktadır. Radyo Frekans (RF) ve mikrodalga (MW) alanları kapsayan $3 \mathrm{kHz}-300 \mathrm{GHz}$ frekans bandında yer alan elektromanyetik alanlar ile çalışan bu teknolojiler 40 yıla yakın süredir varlığını sürdürmektedir. Günümüzde kullanılan teknolojilerde Birinci nesil (G) teknolojilerine kıyasla daha yüksek frekans ve enerji kullandığı görülmektedir. Yeni nesil $5 \mathrm{G}$ ve $6 \mathrm{G}$ teknolojilerinde daha yüksek frekanslı ve enerjili milimetre dalgalar (MMW) ve terahertz frekanslı dalgalar kullanılacaktır. $\mathrm{Bu}$ teknolojilerin gelişimiyle artan bilgi paylaşım hızından yararlanan bazı gruplar, son günlerin en önemli sağlık problemi olan Korona virüs (COVID-19) pandemisinin yayılmasında cep telefonu ve baz istasyonu radyasyonu maruziyetini sorumlu tutmuştur. Bu derlemede önceki nesiller ve yeni nesil cep telefonu teknolojilerinin sağlık etkilerine iliş̧in bilimsel yayınlar incelemiştir.

Anahtar Kelimeler: Radyo Frekans, 5G, Cep Telefonu, COVID-19, Elektromanyetik Alan, Olumsuz Sağlık Etkisi

\begin{abstract}
There is no definitive information about the health and biological effects of wireless technologies that surround us with an increasing amount every day. These technologies, which work with electromagnetic fields in the $3 \mathrm{kHz}-300 \mathrm{GHz}$ frequency band covering Radio Frequency (RF) and microwave (MW) fields, have been in existence for nearly 40 years. It is seen that the technologies used today use higher frequency and energy compared to the first generation (G) technologies. In the new generation $5 \mathrm{G}$ and $6 \mathrm{G}$ technologies, higher frequency and energy millimeter waves (MMW) and terahertz frequency waves will be used. Benefiting from the increasing speed of information sharing with the development of these technologies, some groups have blamed mobilephone and base station radiation exposure in the spread of the Corona virüs (COVID-19) pandemic, the most important health problem of recent days. In this review, scientific publications on the health effects of previous generations and new generation mobile phone technologies were examined.
\end{abstract}

Key words: Radiofrequency, 5G, Mobile Phone, COVID-19, Electromagnetic Field, Adverse Health Effect

Yazışma Adresi: Elçin Özgür Büyükatalay, Gazi Üniversitesi Tıp Fakültesi Dekanlık Binası, Yenimahalle / Ankara

E-Posta: elcinozgur@gazi.edu.tr

Alınma tarihi: 04.12.2020 / Kabul tarihi: 21.12.2020 / Yayımlanma tarihi: 20.09.2021

Cep Telefonu ve Sağlık - Küçükbağrıaçık ve Büyükatalay 
bulunmazken; bazıları bu alanların etkili olduğunu savunmaktadır. RF alan maruziyeti üzerine yapılan çalışmalarda; kanser (4), genetik Günümüzün modern hayatında vazgeçilmez hale gelen kablosuz iletişimin sağlık etkileri hala tam olarak açıklığa kavuşmuş değildir. $\mathrm{Bu}$ belirsizlik nedeniyle sansasyona açık bir konu olan cep telefonu teknolojileri ve tüm dünyanın en önemli gündem maddesi olan Korona virüs (COVID-19) salgını ile ilişkili olduğunu söyleyen gruplar bulunmaktadır. Yeni nesil cep telefonları teknolojileri ve sağlık etkileri hakkında bilgi sahibi olabilmek için bu teknolojilerde kullanılan elektromanyetik alanlar hakkında bilgi sahibi olmak gerekmektedir.

Cep telefonu frekansları elektromanyetik alanların Radyo frekans (RF) ve Mikrodalga diye adlandırılan $3 \mathrm{kHz}-300 \mathrm{GHz}$ frekans bandında yer alır (1). RF alanların temel bileşenleri (i) frekansı (Hz); (ii) radyasyon yoğunluğu veya güç yoğunluğu $\left(\mathrm{W} / \mathrm{m}^{2}\right.$ veya $\mu \mathrm{W} / \mathrm{cm}^{2}$ ); (iii) modülasyonu; ve (iv) sürekli veya kesikli radyasyon paternidir. Vücutta emilen RF alanın enerjisi için ise özgül soğurma oranı (Spesific Absorption Rate- SAR; W/kg) parametresi kullanılır. Mobil İletişim İçin Küresel Sistem (Global System for Mobile Communications, GSM) mobil iletişim için kullanılan en yaygın frekans bantları 850, 900, 1800, 1900 ve $2100 \mathrm{MHz}$ frekanslardır. Mobil telefon sistemlerinin teknolojik gelişmelere bağlı olarak frekansları artmaktadır.

Mobil telefon sistemleri ise 0. nesil (Generation, G) olarak adlandırılan ilk nesil sistemler ile başlamış ve sırası ile $1 \mathrm{G}, 2 \mathrm{G}, 2.5 \mathrm{G}$, 3G, 4G sitemler kullanılmaktadır. Gelecekte 5G teknoloji ile veri aktarımındaki çok ufak sapmalar sayesinde; otonom sürüş ve hatta uzaktan cerrahi operasyonların yapılması mümkün olacaktır (2-3). Cep telefonu teknolojisindeki gelişmeler genel olarak dört farklı nesile göre sınıflandırılmaktadır. İlk nesil ağlar (1G) 1980»lerin ortalarında kullanıma sunulmuş olup; dünyanın farklı ülkelerinde Kuzey Amerika da gelişmiş cep telefonu sistemi (Advanced Mobile Phone System, AMPS), Avrupa'da toplam erişim iletişim sistemleri (Total Access Communication System, TACS) kullanılıyordu. Analog teknolojiye dayanan bu sistemler, sesli iletişim hizmetleri sunmak için frekans modülasyonunu kullanmaktaydılar. Gelişen teknoloji sonucunda 2000 yılına gelindiğinde görevlerini tamamlayarak kapatıldılar. Spektral verimliliği artırmak için ses kodlaması kullanan dijital teknolojiye dayanan ikinci nesil ağlar (2G) 1990'ların başında kurulmaya başlandı. Sistem zaman bölümlü çoklu erişim (Time Division Multiple Access, TDMA) frekans kanallarını Avrupa'da mobil iletişim için küresel sistem (Global System for Mobile Communications, GSM), Japonya da Kişisel Dijital Hücresel (Personal Digital Cellular, PDC) kullanmaktadır. 2G sistemleri bazı temel veri hizmetlerini içerecek şekilde genişletildi, daha sonraki veri hizmetlerine sahip sistemler genellikle 2.5G olarak adlandırıldı. Kapsamlı veri hizmetleri sunan üçüncü nesil cep telefonları (3G) 2000'li yılların başında kullanıma sunuldu. $\mathrm{Bu}$ telefonlar günümüzün akıllı telefonların başlangıcıdır. $\mathrm{Bu}$ sistemler kod bölmeli çoklu erişim (Code Division Multiple Access, CDMA) radyo veri yöntemlerini kullanır. Dördüncü nesil (4G) teknoloji ise artan veri hizmetleri talebini karşılamak için kullanıma sunulmaya başlandı. Bu sistemler uzun süreli gelişim (Long Term Evolution, LTE) olarak bilinir ve dikgen frekans bölmeli çoğullama (Orthogonal Frequency Division Multiplexing, OFDM) erişimini temel almaktadır (3). Geçmiş de kullanılan ve günümüz de kullanılmakta olan cep telefonu frekanslarının canlı üzerindeki biyolojik etkilerine yönelik literatürde in-vivo ve in-vitro pek çok çalışma bulunmaktadır. Ancak bu çalışmaların bazılarında etki

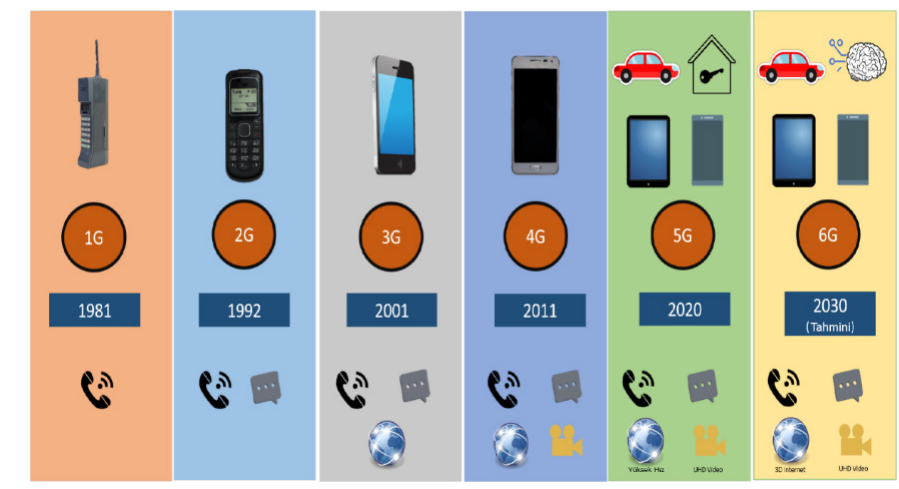

Resim 1: Mobil iletişim ağların zaman içinde ki gelişimi (17)

\section{G ile Artan Frekans Bantlarının Biyolojik Etkileri}

Uluslararası İyonize Olmayan Radyasyondan Korunma Komisyonu (International Commission on Non-Ionizing Radiation Protection, ICNIRP) RF radyasyonu için 11 Mart 2020 de 100 kHz-300 GHz aralığında ki (5G frekansını da kapsıyor) elektromanyetik alanlara maruz kalmaya ilişkin yeni bir yönerge yayınladı (18). ICNIRP 1998 yayınladığı yönergede genel halk için ortalama 6 dakikadan fazla RF frekansları 2-6 GHz (bu frekans 5G frekansını da içermektedir) maruziyeti $10 \mathrm{~W} / \mathrm{m}^{2}$ (1) iken 2020 de yayınladığı yeni yönetmelik de bu değeri $40 \mathrm{~W} / \mathrm{m}^{2}$ (18) yükseltilmiştir. Böylece $5 \mathrm{G}$ 'nin oluşturacağ 1 yüksek güç yoğunluğu ile standartlar da uyumlu hale getirilmiştir. Ancak, ICNIRP standart değerlerini belirlerken bu alanların sadece termal etkileri ile almakta ve termal olmayan etkileri ise göz ardı etmektedir (19-21).

Cep Telefonu ve Sağlık - Küçükbağrıaçık ve Büyükatalay 
Bilim insanlarına göre $5 \mathrm{G}$ teknolojisi etik bir sorunu da ortaya çıkarmaktadır. Nasıl ki bir bireyin bilgisi ve imzalı izni olmadan yeni bir ilacın bireyler üzerinde denenmesi mümkün değilse, bu tür ilkelerin bilinmeyen yeni ve yeterince test edilmemiş bir teknoloji olan $5 \mathrm{G}$ için de geçerli olması gerektiğini düşünülmektedirler. Günlük hayatta $5 \mathrm{G}$ teknolojilerinden kaynaklı RF radyasyonuna maruz kalma, potansiyel sağlık riskleri içeren tıbbi bir deney olarak görülmektedirler (22). İnsan yapımı RF elektromanyetik alanlara yaşam süresi boyunca maruz kalan ilk nesil olduğumuzdan sağlığımız üzerine etkilerinin belirlenmesi yıllar ve hatta on yıllar alacaktır (15). Diğer bir sorun ise artan kablosuz ağlar nedeniyle neredeyse bir popülasyondaki hemen hemen herkesin günlük hayatlarında RF elektromanyetik alanlara maruz kalıyor olması nedeniyle, yapılacak epidemiyolojik çalışmalar için kontrol grubu bulunamayacaktır.

Uluslararası Kanser Araştırma Ajansı (International Agency for Research on Cancer, IARC), 2011 yilında RF radyasyonu "Grup 2B-olası kanserojen” olarak sınıflandırmıştır (23). Tütün ve sigaranın kullanımının "Grup 1A karsinojen" sinıflandırmasına girebilmesi için geçen uzun süre dikkate alındığında, RF radyasyonunun hala bu zamanın başında olduğu göz ardı edilmemelidir (22).

Gelişen bu senaryoda, 5G iletişim sistemlerinin biyolojik etkileri çok az araştırılsa da, 5G ağlarının geliștirilmesine yönelik uluslararası bir eylem planı başladı. 5G ile kullanılacak milimetre dalgaların; cilt sıcaklığını artırdığı, gen ekspresyonunu değiştirdiği, hücresel çoğalmayı teşvik ettiği ayrıca oksidatif stres, enflamatuar ve metabolik süreçlerle bağlantılı proteinlerin sentezinde değişikliklere, oküler hasarlar oluşturabileceğini, nöron-kas dinamiklerini etkileyebileceği gösterilmiştir. Genel olarak radyo RF-EMF ve özel olarak da MMW'nin sağlık üzerindeki etkilerini daha iyi ve bağımsız bir şekilde anlamak için fazla çalışmaya ihtiyaç vardır (24). Simko ve arkd. $6-100 \mathrm{GHz}$ frekansı aralığında yapılan in vivo veya in vitro 94 araştırmayı analiz ettiğinde, in vivo çalışmaların \% 80 i maruziyete yanıt verirken, in vitro çalışmaların \% 58 in de biyolojik cevaplar görülmüş. Güç yoğunluğu, maruz kalma süresi, sıklığı veya frekansı ile maruziyet etkileri arasında tutarlı bir ilişki gözlenmemiş. Mevcut çalışmalar, anlamlı bir güvenlik değerlendirmesi için ve termal olmayan etkiler hakkındaki soru işaretleri için yeterli ve nitelikli bilgi sağlamamaktadır (25). 5G ağların da kullanılacak olan 6-100 $\mathrm{GHz}$ frekanslar aralığındaki çalışmaları incelendiğimiz de; $60 \mathrm{GHz}$ frekans da $0.5 \mathrm{~mW} / \mathrm{cm}^{2}$ güç yoğunluğunda 5 gün boyunca günlük 30 dakika MMW maruziyete bırakılan sağlıklı ve Lewis tümör hücresi enjekte edilmiş farelerde, tümörün büyümesini arttırmış ve sağl1klı fareler de ise motor aktivitesinde artışa neden olmuştur. Bu etkiler göz önüne alındığında iç mekân iletişimleri için $60 \mathrm{GHz}$ 'lik bir dalga kullanmadan önce ihtiyatlı davranılmalıdır (26). MMW'nın etkileri ( $60 \mathrm{GHz}, 475 \mathrm{~mW} / \mathrm{cm}^{2}, 1.898 \mathrm{~mW} / \mathrm{cm}^{2}, 6$ ve 30 dak.) tavşan gözlerindeki etkisi incelenen çalışma da göz de çeşitli tip ve seviye de akut termal yaralanmalar tanımlamışlar. Milimetre dalgalarının neden olduğu termal etkiler, göz yüzeyinin altına da nüfuz edebilir (27). Bununla birlikte, şu anda herhangi bir önlem alınmazsa kötüleşen halk sağlığı ve ekolojik sisteme verilen zararlar açısından topluma maliyeti büyük olasıllkla çok yüksek olacaktır (22). 5G mobil ağ teknolojisi genel olarak inanıldığ gibi yalnızca cildi ve gözleri etkilemeyeceği aynı zamanda olumsuz sistemik etkilere yol açabileceği dair kanıtlar sunulmaktadır $(15,28)$.

5G teknolojisi sanal dünya ile benzersiz entegrasyonu vaat etmektedir (29). 2025 yılına kadar 5G ağ dünya nüfusunun yaklaşık \% 55-65 ini kapsayacağını̈öngörülmektedir(30). Bu da yaklaşı 2.6 milyaraboneye denk geldiği göz önüne alındığında telekomünikasyon şirketlerinin bu kadar büyük bir pazardan vazgeçmeleri mümkün görünmemektedir. Yüksek veri aktarım hızlarına duyulan ihtiyaç, iletişim endüstrisini $\mathrm{THz}$ altı frekans spektrumuna doğru itmektedir fakat öyle görünüyor ki bu tür bir lüksün ödenmesi gereken bazı bedelleri olacaktır. $5 \mathrm{G}$ baz istasyonları ile şehirlerimizi, çalışma alanımızı ve evlerimiz de benzeri görülmemiş bir elektromanyetik dumanıyla yaşamak zorunda kalacağız. Radyo frekans radyasyon, çevre kirliliğinin yeni bir biçimi olarak giderek daha fazla kabul görmektedir. Ne kadar faydalı olursa olsun sağlık üzerine etkileri henüz keşfedilmemişken olası sağlık sorunları görmezden gelinemez. Cilt katmanın da termal olmayan biyolojik etkilere yol açabileceğini söylemek için yeterli kanıt vardır. Olası biyolojik etkileri araştırılmalı ve 5G iletişimlerin uygulanmasına yönelik standartların tanımlanmasın da göz önüne alınmalıdır. Halk sağlığı için olası sonuçları araştırılmadan önce, iletişim için alt $\mathrm{THz}$ teknolojilerinin sınırsız kullanımına karşı temkinli olunmalıdır (31).

\section{COVID-19 ve 5G}

Aralık 2019 da Çin〉in Wuhan kentinde ilk vakanın görülmesi ile başlayan COVID-19 salgını dünya çapında hızla yayıldı ve yayılmaya devam etmektedir. Çeşitli sosyal medya platformlarında 5G teknolojisinin COVID-19 virüsünün yayılımının artmasına neden olduğuna dair komplo teorileri üretildi. En popüler teoriler arasında yer alan 5G'nin COVID-19'un yayılmasını hızlandırıyor söylentileri sonucun da İngiltere de birçok 5G kulesinin tahribatıyla sonuçlanmıştır. Literatür taramamızda 5G'nin COVID-19'u yaydığına dair hiçbir bilimsel makale bulunamamıştır. 5G ve COVID-19 arasında ilişki olduğu iddiaları gazete ve sosyal medya haberlerinden ibarettir ve hiçbir bilimsel dayanağı yoktur. Virüsler radyo dalgalarıyla taşınamazlar. Covid-19; radyo dalgalarıyla, mobil ağlar ile özellikle de 5G mobil ağlar ile yayılamazlar (32-33). COVID-19 pandemi süreci ile değişen hayatımızın bir parçası olan; çevrimiçi toplantı ve öğrenim, ofis ortamının eve taşınması, e-alışverişin popülitesinin artması, e-sosyalleşmenin artışı ile bağlantılı olarak daha hızlı ve kaliteli veri aktarım talepleri $5 \mathrm{G}$ ve $6 \mathrm{G}$ teknolojisinin işine yarayacak gibi görünmektedir. Ayrıca 5G'nin sunduğu dijital sağlık hizmetleri ile COVID-19salgınına karşı mücadelede rol alacaktır (34-35). 5G ağlarının COVID-19 salgının yayılması üzerine bir etkisi yok iken, COVID-19'un 5G teknolojisinin yayılmasına önemli etkisi olacak gibi görünmektedir.

5G teknolojisi insanlığa daha rahat ve kolay yaşam tarzı sunmasına rağmen daha kısa dalga boyuna sahip radyo frekans radyasyonu ile sağlık ve güvenlik sorularının ortaya çıkmasına neden olabilir. Mevcut $2 \mathrm{G}, 3 \mathrm{G}$ ve $4 \mathrm{G}$ kablosuz teknolojilerinden kaynaklanan zararlar konusunda bilim insanları arasında bir fikir birliğine varılmamışken ve tartışmalar sürerken, $5 \mathrm{G}$ ve gelecekteki $6 \mathrm{G}$ teknolojisiyle giderek artan yüksek frekansların kullanımının insan ve çevresel etkileri oldukça az incelenmiş olması toplumun endişelerini arttırmaktadır. Hızla gelişen ağ teknolojisi ile biyolojik ve ekosistem üzerindeki etkilerinin araştırıldığ 1 çalışmalar eş güdümlü gitmemektedir. Bu bilinmezlikler hem fiziksel hem de ruhsal sağlik perspektifinden olumsuz halk sağlığı sorunlarına yol açacaktır. Bu kadar bilinmezliğin olduğu ve giderek artan yüksek frekanslara karşı ihtiyat ilkesi gereği temkinli yaklaşılmalıdır. 


\section{Kaynaklar}

1.Guidelines for limiting exposure to time-varying electric, magnetic, and electromagnetic fields (up to $300 \mathrm{GHz}$ ). International Commission on Non-Ionizing Radiation Protection. Health Phys 1998;74(4):494-522.

2.Li D. 5G and intelligence medicine-how the next generation of wireless technology will reconstruct healthcare? Precision clinical medicine. 2019;2(4):205-208.

3.Exposure to high frequency electromagnetic fields, biological effects and health consequences (100 kHz to $300 \mathrm{GHz}$ ). Germany: ICNIRP; International Commission on Non-Ionizing Radiation Protection; 2009a.

4.Morgan LL, Miller AB, Sasco A, Davis DL. Mobile phone radiation causes brain tumors and should be classified as a probable human carcinogen (2A) (Review). International Journal of Oncology 2015;46(5):1865-1871

5.Sahin D, Ozgur E, Guler G, et al. The 2100MHz radiofrequency radiation of a 3G-mobile phone and the DNA oxidative damage in brain. Journal of Chemical Neuroanatomy 2016;75:94-98

6.Esmekaya MA, Aytekin E, Ozgur E, et al. Mutagenic and morphologic impacts of $1.8 \mathrm{GHz}$ radiofrequency radiation on human peripheral blood lymphocytes (hPBLs) and possible protective role of pre-treatment with Ginkgo biloba (EGb 761). Science of The Total Environment 2011;410-411:59-64.

7.Jiang D-P, Li J-h, Zhang J, et al. Long-term electromagnetic pulse exposure induces Abeta deposition and cognitive dysfunction through oxidative stress and overexpression of APP and BACE1. Brain Research 2016;1642:10-19.

8.Kim JH, Yu D-H, Huh YH, et al. Long-term exposure to $835 \mathrm{MHz}$ RF-EMF induces hyperactivity, autophagy and demyelination in the cortical neurons of mice. Scientific Reports 2017;7(1):41129.

9.Altun G, Deniz ÖG, Yurt KK, Davis D, Kaplan S. Effects of mobile phone exposure on metabolomics in the male and female reproductive systems. Environ Res 2018;167:700 707.

10.Falzone N, Huyser C, Becker P, Leszczynski D, Franken DR. The effect of pulsed 900$\mathrm{MHz}$ GSM mobile phone radiation on the acrosome reaction, head morphometry and zona binding of human spermatozoa. Int J Androl 2011;34(1):20-26.

11.Kazemi E, Mortazavi SM, Ali-Ghanbari A, et al. Effect of $900 \mathrm{MHz}$ Electromagnetic Radiation on the Induction of ROS in Human Peripheral Blood Mononuclear Cells. J Biomed Phys Eng 2015;5(3):105-114.

12.Ohtani S, Ushiyama A, Maeda M, et al. The effects of radio-frequency electromagnetic fields on T cell function during development. J Radiat Res 2015;56(3):467-474

13.Gruber MJ, Palmquist E, Nordin S. Characteristics of perceived electromagnetic hypersensitivity in the general population. Scand J Psychol 2018;59(4):422-427.

14. Son Y, Kim JS, Jeong YJ, et al. Long-term RF exposure on behavior and cerebral glucose metabolism in 5xFAD mice. Neurosci Lett 2018;666:64-69.

15.Russell CL. $5 \mathrm{G}$ wireless telecommunications expansion: Public health and environmental implications. Environmental Research 2018;165:484-495.

16.Simko M, Mattsson MO. 5G Wireless Communication and Health Effects-A Pragmatic Review Based on Available Studies Regarding 6 to $100 \mathrm{GHz}$. Int J Environ Res Public Health 2019;16(18)

17. Chataut R, Akl R. Massive MIMO Systems for $5 \mathrm{G}$ and beyond Networks-Overview, Recent Trends, Challenges, and Future Research Direction. Sensors 2020;20(10):2753.

18.Guidelines for Limiting Exposure to Electromagnetic Fields (100 kHz to $300 \mathrm{GHz}$ ). Health Physics 2020;118(5):483-524.

19. Hardell L, Carlberg M. Health risks from radiofrequency radiation, including 5G, should be assessed by experts with no conflicts of interest. Oncol Lett 2020;20(4):15.

20.Belpomme D, Hardell L, Belyaev I, Burgio E, Carpenter DO. Thermal and non-thermal health effects of low intensity non-ionizing radiation: An international perspective. Environ Pollut 2018;242(Pt A):643-658.

21.Miller AB, Morgan LL, Udasin I, Davis DL. Cancer epidemiology update, following the 2011 IARC evaluation of radiofrequency electromagnetic fields (Monograph 102)

Genel Tip Derg 2021;31(3)309-312
Environ Res 2018;167:673-683.

22.Hardell L, Nyberg R. Appeals that matter or not on a moratorium on the deployment of the fifth generation, 5G, for microwave radiation. Mol Clin Oncol 2020;12(3):247-257

23.Hardell L. World Health Organization, radiofrequency radiation and health - a hard nut to crack (Review). International Journal of Oncology 2017;51(2):405-413.

24.Di Ciaula A. Towards 5G communication systems: Are there health implications? Int J Hyg Environ Health 2018;221(3):367-375

25.Simko M, Mattsson MO. 5G Wireless Communication and Health Effects-A Pragmatic Review Based on Available Studies Regarding 6 to $100 \mathrm{GHz}$. International Journal of Environmental Research and Public Health 2019;16(18):3406.

26.Rocher C, Ruelloux M, Himdi M, et al. Biological effects of millimeter wave irradiation on mice-preliminary results. IEEE Transactions on Microwave Theory and Techniques 2000;48(11):2104-2110.

27.Kojima M, Hanazawa M, Yamashiro Y, et al. Acute Ocular Injuries Caused By 60-Ghz Millimeter-Wave Exposure. Health Physic. 2009;97(3).

28.Kostoff RN, Heroux P, Aschner M, Tsatsakis A. Adverse health effects of $5 \mathrm{G}$ mobile networking technology under real-life conditions. Toxicol Lett 2020;323:35-40.

29.Agiwal M, Roy A, Saxena N. Next Generation 5G Wireless Networks: AComprehensive Survey. IEEE Communications Surveys \& Tutorials 2016;18(3):1617-1655.

30.Reichert C. 5G customers predicted to hit 2.6 billion in 2025. 2019; Available at: https://www.cnet.com/news/5g-customers-predicted-to-hit-2-6-billion-in-2025/ Erişim tarihi 01 Aralık 2020. (Accessed December 01, 2020).

31.Betzalel N, Ben Ishai P, Feldman Y. The human skin as a sub-THz receiver - Does 5G pose a danger to it or not? Environmental Research 2018;163:208-216.

32.Ahmed W, Vidal-Alaball J, Downing J, López Seguí F. COVID-19 and the 5G Conspiracy Theory: Social Network Analysis of Twitter Data. Journal of Medical Internet Research 2020;22(5):e19458.

33.WHO. Coronavirus disease (COVID-19) advice for the public: Mythbusters. 2020; Available at: https://www.who.int/emergencies/diseases/novel-coronavirus-2019/advicefor-public/myth-busters\#5g Erişim tarihi 01 Aralık 2020. (Accessed December 01, 2020).

34.Siriwardhana Y, Gür G, Ylianttila M, Liyanage M. The role of 5G for digital healthcare against COVID-19 pandemic: Opportunities and challenges. ICT Express 2020. https:// doi.org/10.1016/j.icte.2020.10.002

35.Klemeš JJ, Fan YV, Jiang P. COVID-19 pandemic facilitating energy transition opportunities. International journal of energy research 2020:10.1002/er.6007. 